\title{
Photolysis of caged calcium using a low-cost flash unit: efficacy analysis with a calcium selective electrode
}

\author{
G.A. VAN KOEVERINGE and R. VAN MASTRIGT
}

Department of Urology, Division of Urodynamics, Erasmus University Rotterdam, The Netherlands

\begin{abstract}
Photolysis of caged calclum (Nitr5 8 , Calbiochem) can be used to study calcium dependent processes such as excitation-contraction coupling and muscular mechanics. Expensive high energy light sources are routinely used for UV light exposure, but this study describes an alternative low cost xenon flash unit constructed in our laboretory. A $300 \mathrm{~J}$ short arc xenon flash lamp (Hoimann) was mounted in an elliptical reflector and driven by a modified Metz 60 CT 4 photoflash unit up to $240 \mathrm{~J}$ Input energy and 4 ms flash duretion. A $20 \mu \mathrm{l}$ cuvette containing a test solution was placed in a complementary elliptical refloctor. An ion selective calcium electrode was used to measure the free caicium concentration $\left[\mathrm{Ca}^{2+}\right]$ before and after flash in test solutions containing $1.00 \mathrm{mM}$ Nitr5 in comblnation with different added $\left[\mathrm{Ca}^{2+}\right]$ s. Using this technique we estlmeted that 1 flash on $1.00 \mathrm{mM}$ Nitrs Increased the free $\left[\mathrm{Ca}^{2+}\right]$ from $10^{-7}$ to $1.1 \times 10^{-5} \mathrm{M}$. When the added $\left[\mathrm{Ca}^{2+}\right]$ was less than $2.3 \times 10^{-4} \mathrm{M}$, the used Nitrs behaved as a strong calclum chelator because $20 \%$ of it was unloaded with calcium. It is concluded that a physiologically relovant change in free [ $\mathrm{Ca}^{2+}$ ] can be evoked by photolysis of Nitrs using a low cost (approximately $\$ 1500$ ) xenon flash unit, and that lon selective Ca electrodes can be adequately used to monitor the resulting changes in $\left[\mathrm{Ca}^{2+}\right]$.
\end{abstract}

Photolabile calcium chelators have been designed to study intracellular calcium dependent processes [1,2]. These 'caged' calcium compounds are useful tools to bypass rate limiting steps in muscular excitation-contraction coupling [3-5]. When using the chelators intracellularly [6-8], it is possible to evoke a stepwise increase in the intracellular calcium concentration $\left[\mathrm{Ca}^{2+}\right]$ by exposing the cells to high intensity ultra-violet (UV) light. The minimum energy density required for photolysis of the caged calcium compound Nitr5 is approximately 250 $\mathrm{mJ} / \mathrm{cm}^{2}$ in a wavelength band from $320-370 \mathrm{~nm}$ $[9,10]$. The commonly used frequency doubled ruby laser $[6,7]$ meets these specifications in a flash duration of $25 \mathrm{~ns}$, but is very expensive. When a longer flash duration, $\pm 4 \mathrm{~ms}$, is acceptable, the commercially available xenon flashlamp developed by Rapp and Guth [11] can be used. Even at one fourth of the price of the laser, this is still not a very economical altemative. We decided to develop a UV 


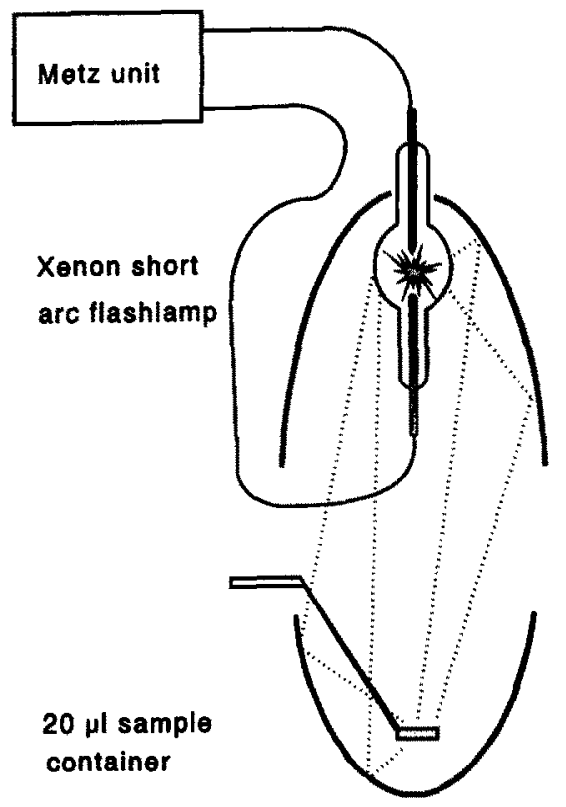

Fig. 1 A schematic representation of the fluid sample illumination setup. A short arc xenon flash lamp was mounted in an elliptical reflector and driven by a modified Metz $60 \mathrm{CT} 4$ photo flash unit A $20 \mu$ cuvette was placed in a complementary second elliptical reflector.

light source for the release of caged $\mathrm{Ca}$ based on a standard photo flashlamp, costing one tenth of the price of the commercially available xenon flash unit.

The efficacy of the developed UV light source was quantified by measuring the increase in free calcium after exposure of a $20 \mu \mathrm{l}$ sample of caged calcium with a calcium selective electrode.

\section{Materials and methods}

\section{Ultra-violet light source}

A modified Metz 60 CT 4 flash unit was used as an ultra-violet (UV) light source for the photolysis experiments. When this unit is used for photographic applications, the UV light from the flashtube is $a b$ sorbed by a filter in the front window.

This front window was removed and the $70 \mathrm{~mm}$ long flashtube was replaced by a $300 \mathrm{~J} /$ flash, 120 W, type DG 8907 ST II xenon flashtube manufac- tured by Heimann, Wiesbaden, Germany. This short arc lamp (arc length $7 \mathrm{~mm}$ ), was placed in the focus of a Melles and Griot, type 02 REM 001 elliptical mirror.

In order to compensate for the lower impedance of this lamp (20 mohm) as opposed to the original $70 \mathrm{~mm}$ tube $(1.5 \mathrm{ohm})$, an extra choking coil of 22 $\mu \mathrm{H}$ was placed in the high power circuit of the Metz unit in series with the short arc tube. The trigger circuit of the driver unit was not altered. The focus size, determined by video tape recording of flashes on a graduated grey plastic screen, was approximately $5 \mathrm{~mm}$ in diameter. Flash duration was $4 \mathrm{~ms}$ measured by means of a photo detector with amplifier connected to a storage oscilloscope and the input energy was calculated to be $240 \mathrm{~J}[12,13]$.

\section{Fluid sample illumination setup}

A $20 \mu \mathrm{l}$ fluid sample was exposed in a $7 \mathrm{~mm}$ long quartz tubular container of $1.8 \mathrm{~mm}$ inner diameter and $200 \mu \mathrm{m}$ wall thickness that was placed in the second focus of the elliptical reflector, as shown in Figure 1. In order to gain a more intense and even exposure the container was surrounded by a custom made second elliptical reflector complementary to the 02 REM 001. A cedar wooden mould was made for this reflector using a computerized milling machine. The glass for the reflector was blown inside this mould to a wall thickness of $2 \mathrm{~mm}$. The inside surface of the elliptically shaped glass was coated with aluminium.

\section{Ion-selective calcium electrode setup}

A calcium-selective electrode, Orion type 9320, was used in combination with a double barrel reference electrode, Orion type 900200 (inner compartment filled with saturated $\mathrm{AgCl}$ solution and outer compartment with $4 \mathrm{M} \mathrm{KCl}$ ), for the measurement of free $\left[\mathrm{Ca}^{2+}\right]$ in the $20 \mu$ sample. Initially, a setup was tested in which a continuous flow of fluid was pumped via the Ca selective electrode past the reference electrode with a syringe pump. The following (Fig. 2) simpler assembly, however, showed far more stable potentials. In this setup (Fig. 2) the $\mathrm{Ca}$ electrode was positioned upside down and a teflon spacer ring with a thickness of $0.3 \mathrm{~mm}$ (inner 
diameter $6 \mathrm{~mm}$ and outer diameter $12 \mathrm{~mm}$ ) was placed around the $6 \mathrm{~mm}$ diameter $\mathrm{Ca}$ sensitive membrane. The $20 \mu \mathrm{l}$ fluid sample was applied centrally in the ring on the membrane. The reference electrode was gently lowered onto the membrane and loaded with a mass of $1.5 \mathrm{~kg}$, so that a fluid film over the telfon ring made contact with the peripheral junction of the reference electrode. The potential between both electrodes was measured using a Consort $\mathrm{pH}-\mathrm{mV}$ meter and recorded on a $\mathrm{W}+\mathrm{W}$ chart recorder. Values were read after allowing $20 \mathrm{~s}$ for stabilization. The calcium-sensitive membrane, the ring and the reference electrode were rinsed extensively with de-ionised water and dried with a clean tissue between measurements.

\section{Solutions}

For calibration, standard buffer solutions were made containing saturated Ca-EGTA and EGTA in proportions calculated so that free $\left[\mathrm{Ca}^{2+}\right]$ of $10^{-8}, 10^{-7}$,

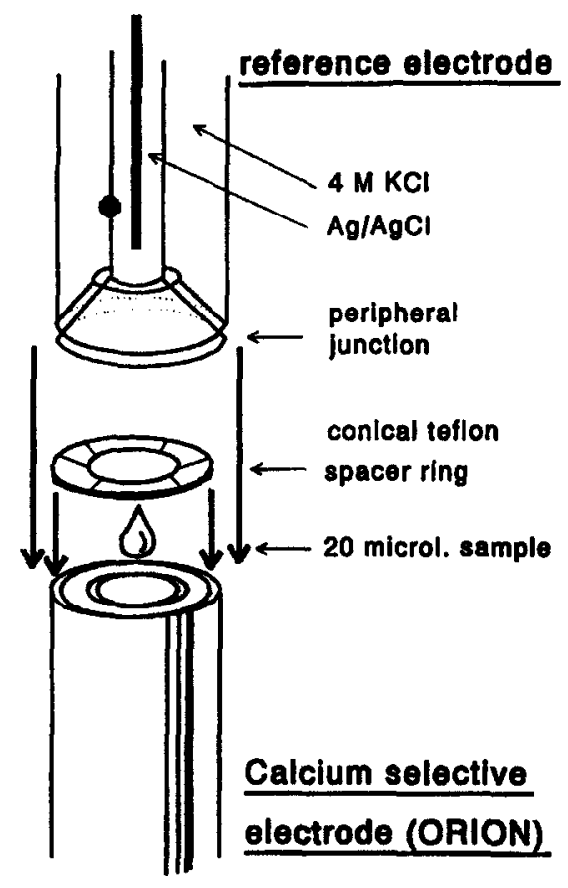

Fig. 2 A schematic representation of the ion selective calcium electrode setup. The calcium selective electrode was positioned upside down, the $20 \mu$ sample was applied centrally on the membrane and the reference electrode was lowered so that a fluid film over the ring made contact with the periphenal junction of the reference electrode.
$10^{-6}$ and $10^{-5} \mathrm{M}$ were established at $\mathrm{pH} 6.8$; total EGTA concentration was $3 \mathrm{mM}$.

Standards with $10^{-4}$ and $10^{-3} \mathrm{M}$ free $\left[\mathrm{Ca}^{2+}\right]$ were made by diluting a $2 \times 10^{-3} \mathrm{M} \mathrm{CaCl}_{2}$ (Merck) standard solution with de-ionised water $\left(\left[\mathrm{Ca}^{2+}\right] 2 \times\right.$ $\left.10^{-6} \mathrm{M}\right)$. The solutions containing Nitr5 (Calbiochem) were composed of 1.00 or $3.00 \mathrm{mM}$ Nitr5 and $10 \mathrm{mM} \mathrm{KCl}$, the $\mathrm{KCl}$ was added to adjust the ionic strength (according to Orion $\mathrm{Ca}^{2+}$ selective electrode manual). $\mathrm{CaCl}_{2}$ was added in order to obtain solutions with 11 different added $\left[\mathrm{Ca}^{2+}\right] \mathrm{s:} 10^{-7}$, $10^{-6}, 10^{-5}, 5 \times 10^{-5}, 10^{-4}, 1.5 \times 10^{-4}, 2 \times 10^{-4}, 2.5$ $\times 10^{-4}, 3 \times 10^{-4}, 5 \times 10^{-4}, 10^{-3} \mathrm{M}$.

\section{Measurement protocol}

Ion-selective electrode (ISE) potentials were measured 5 times in the 6 different free $\mathrm{Ca}$ standard solutions in ascending order. Before and after a series of measurements using Nitr5, the electrode response was checked with 3 different standards: $10^{-6}$, $10^{-5}$, and $10^{-4} \mathrm{M} \mathrm{Ca}$. The free $\left[\mathrm{Ca}^{2+}\right] \mathrm{s}$ of the solutions containing $1.00 \mathrm{mM}$ Nitr5 were measured 5 times in both flashed and unflashed condition for each of the solutions with different added $\left[\mathrm{Ca}^{2+}\right] \mathrm{s}$. The $10^{-7}, 10^{-6}, 10^{-5}$ and $10^{-4} \mathrm{M}$ added $\left[\mathrm{Ca}^{2+}\right]$ solutions, the $10^{-4}, 1.5 \times 10^{-4}, 2 \times 10^{-4}, 2.5 \times 10^{-4}, 3 \times$ $10^{-4} \mathrm{M}\left[\mathrm{Ca}^{2+}\right]$ solutions and the $3 \times 10^{-4}$ and $10^{-3}$ $\mathrm{M}\left[\mathrm{Ca}^{2+}\right]$ solutions were measured in separate sessions with intermediate reloading of the $\mathrm{Ca}$ electrode in high $\left[\mathrm{Ca}^{2+}\right]$. Solutions containing $3 \mathrm{mM}$ Nitr 5 were analyzed 3 times, in both flashed and unflashed condition in 3 different solutions with added $\left[\mathrm{Ca}^{2+}\right] 10^{-4}, 5 \times 10^{-4}$ and $10^{-3} \mathrm{M}$. The unflashed Nitr5 solutions were incubated in the $20 \mu \mathrm{l}$ container in front of the flash lamp for the same period of time as the flashed solutions. Both flashed and unflashed solutions were transferred to the $\mathrm{Ca}^{2+}$ measurement site with a $20 \mu \mathrm{l}$ Hamilton syringe approximately $1 \mathrm{~min}$ after the flashes. Between measurements both syringe and container were cleaned thoroughly by flushing several times with de-ionized water. All solutions were flashed 5 times in order to obtain a better readability of the responses. In a separate series $(n=3)$ responses to 1 and 5 flashes were compared using a Nitr5 solution with an added $\left[\mathrm{Ca}^{2+}\right]$ of $2.3 \times 10^{-4} \mathrm{M}$. This solution was also used in a series $(n=3)$ to test Ca release with and with- 


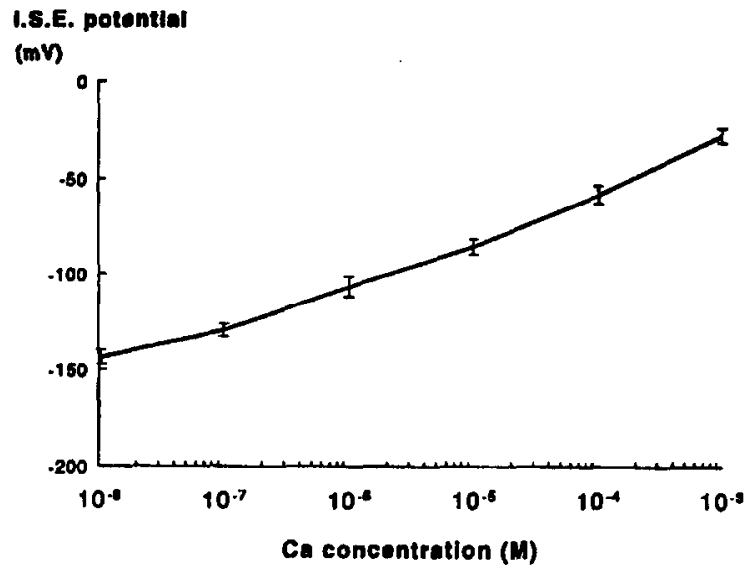

Fig. 3 Calcium electrode calibration curve showing the mean ion selective electrode (ISE) potential \pm standard error of the mean (SEM) for 6 different calcium standard solutions with free $\left[\mathrm{Ca}^{2+}\right]$ of $10^{-8}$ to $10^{-3} \mathrm{M}$. out the complementary second elliptical mirror and with and without a $3 \mathrm{~mm}$ thick UG11 (Schott) glass filter ( $80 \%$ transmission peak between $320-370 \mathrm{~nm}$ wavelength).

\section{Results}

The ISE potential as a function of the free $\left[\mathrm{Ca}^{2+}\right]$, measured in 6 different calcium standard solutions is shown in Figure 3. Figure 4 shows on a double logarithmic scale the free $\left[\mathrm{Ca}^{2+}\right]$ in the Nitr5 buffer solution as a function of the total $\left[\mathrm{Ca}^{2+}\right]$, which is the sum of added $\left[\mathrm{Ca}^{2+}\right]$ and the calcium initially bound to the $1.00 \mathrm{mM}$ Nitr5. Mean \pm standard error of the mean (SEM) for $1.00 \mathrm{mM}$ Nitr5, unphotolysed (solid line) and photolysed (dashed line) are plotted.

Figure 4 also shows a theoretical curve $0 \%$ dotted line) representing the relation between total

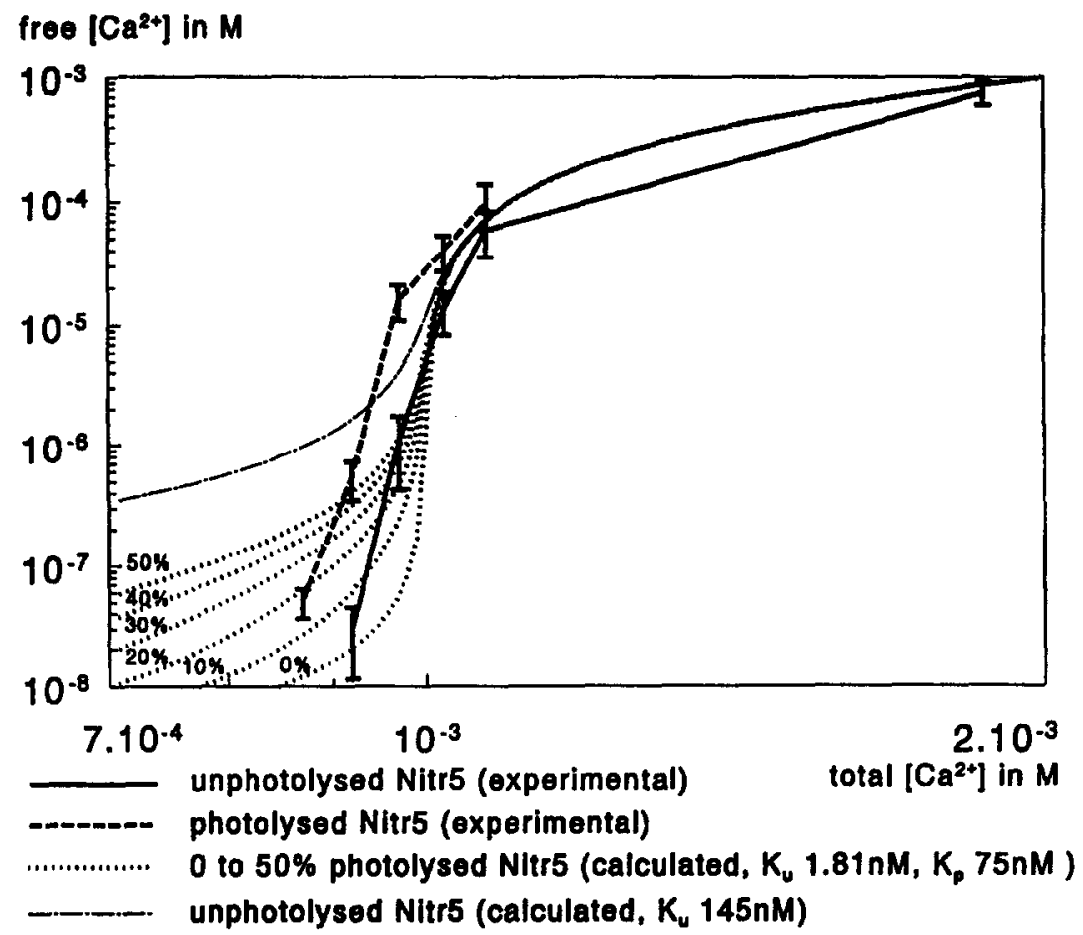

Flg. 4 Free $\left[\mathrm{Ca}^{2+}\right]$ as a function of total $\left[\mathrm{Ca}^{2+}\right]$ i.e. added $\left[\mathrm{Ca}^{2+}\right]$ plus the calcium bound initially to the $10^{-3} \mathrm{M}$ Nitrs. The solid line represents average values \pm SEM for a solution containing $1.00 \mathrm{mM}$ Nitrs. The thick dashed line shows the values for $1.00 \mathrm{mM}$ Nitrs after exposure to 5 UV light flashes. The 6 dotted lines show calculated datu for 6 different degrees of photolysis (from $0 \%$ to $50 \%$ in steps of $10 \%$ ) of a theoretical 2-buffer system, containing unflashed and flashed Nitrs with dissociation constants for calcium of 1.81 $\mathrm{nM}\left(\mathrm{K}_{\mathrm{U}}\right)$ and $75 \mathrm{nM}\left(\mathrm{K}_{\mathrm{P}}\right)$. The dot-dashed line represents a calculated line for unflashed Nitrs using a $\mathrm{Ku}$ of $145 \mathrm{nM}$ (published dissociation constant at $100 \mathrm{mM}$ ionic strength [1]). 
$\left[\mathrm{Ca}^{2+}\right]$ and free $\left[\mathrm{Ca}^{2+}\right]$ in a 2 buffer system (see Appendix). This curve is characterized by a steeply increasing free $\left[\mathrm{Ca}^{2+}\right]$ around a total $\left[\mathrm{Ca}^{2+}\right]$ equal to the [Nitr5] as a result of the $1: 1 \mathrm{Ca}^{2+}$ binding to Nitr5 at saturation. Such a steep part in the curve was also seen in the experimental data measured at different added $\left[\mathrm{Ca}^{2+}\right] \mathrm{s}$. In these data, total $\left[\mathrm{Ca}^{2+}\right]$ in the solutions equalled the added $\left[\mathrm{Ca}^{2+}\right]$ plus the $\left[\mathrm{Ca}^{2+}\right]$ bound initially to the chelator. The amount of $\mathrm{Ca}^{2+}$ bound initially to the chelator was estimated from the horizontal shift between the steep part of the experimental data curve and the comparable part of the theoretical curve. A best fit of both curves was obtained at a value of $0.77 \mathrm{mM}\left[\mathrm{Ca}^{2+}\right]$ being bound to the $1.00 \mathrm{mM}$ Nitr5. Total $\left[\mathrm{Ca}^{2+}\right]$ values in the Nitr5 solution were therefore calculated by adding $0.77 \mathrm{mM}\left[\mathrm{Ca}^{2+}\right]$ to the added $\left[\mathrm{Ca}^{2+}\right]$. The $77 \%$ $\mathrm{Ca}^{2+}$ loading of Nitr5 was verified by measuring free $\left[\mathrm{Ca}^{2+}\right]$ in $3 \mathrm{mM}$ Nitr5 with $10^{-4}, 5 \times 10^{-4}$ and 1 $\times 10^{-3} \mathrm{M}$ added $\left[\mathrm{Ca}^{2+}\right] \mathrm{s}$. In this 3-fold higher [Nitr5] the steep rise in free $\left[\mathrm{Ca}^{2+}\right]$ was expected at a 3-fold higher total $\left[\mathrm{Ca}^{2+}\right]$. Consequently a 3-fold higher amount of added $\left[\mathrm{Ca}^{2+}\right]$ was expected to be necessary to saturate the Nitr5, i.e. $0.69 \mathrm{mM}$. In a limited series of measurements $(n=3)$ the steep free $\left[\mathrm{Ca}^{2+}\right]$ increase was indeed shifted to a value between 0.50-1.00 mM added $\left[\mathrm{Ca}^{2+}\right]$.

Figure 4 shows that after exposing samples with a total $\left[\mathrm{Ca}^{2+}\right]$ between $0.92-1.07 \mathrm{mM}$ to 5 flashes from the flash unit, a significant increase in free $\left[\mathrm{Ca}^{2+}\right]$ was detected. The free $\left[\mathrm{Ca}^{2+}\right]$ was increased

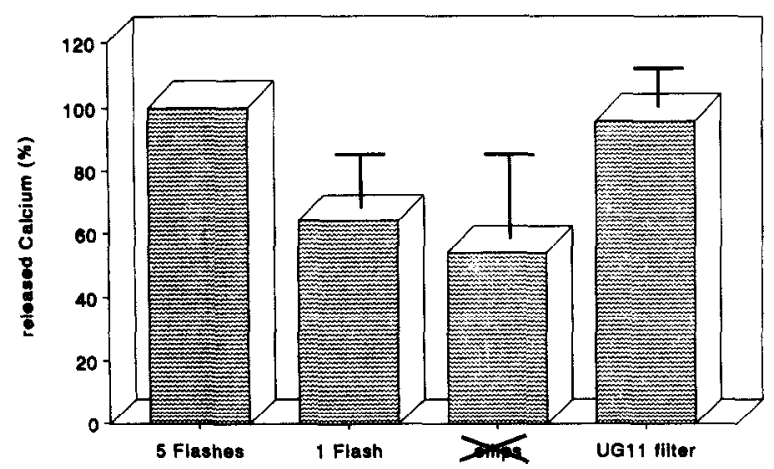

Fig. 5 The relative increase in free $\left[\mathrm{Ca}^{2+}\right]$ evoked by 1 flash, omission of the second complementary elliptical mirror and addition of a Schott UG11 filter expressed as a percentage \pm SEM of the effect of 5 flashes. by a maximum of approximately $2.6 \times 10^{-5} \mathrm{M}$ in response to the flashes in a total $\left[\mathrm{Ca}^{2+}\right]$ of $1.02 \mathrm{mM}$.

The effects of 5 flashes, 1 flash, omission of the complementary elliptical reflector and addition of a UG11 filter in a solution contataing $1.00 \mathrm{mM}$ Nitrs in $1.00 \mathrm{mM}$ total $\left[\mathrm{Ca}^{2+}\right]$ are compared in Fique 5 . One flash released $67 \%$ of the amount of $\mathrm{Ca}^{27} \mathrm{com}$ pared to the amount that was released by 5 flashes. Without a complementary second elliptical refiector 5 flashes released $55 \%$ of the amount released with this reflector. 5 flashes with a UG11 filter released $97 \%$ of the amount released without this filter.

\section{Discussion}

A low cost xenon flash unit was constructed as an alternative for more expensive light sources such as an UV laser or a commercially available xenon flashlamp to photolyse caged calcium. The driver and trigger circuit of a Metz flash unit, which is widely employed in professional photography, was used after slight modification. An additional advantage of this system is that it is battery powered, thus avoiding interference on the power lines. The external trigger system of the photoflash unit could easily be used for synchronization. The original flashtube was replaced by a short-arc xenon flashlamp, which is a more concentrated light source. The UV light emitted by the flashlamp was concentrated using a dual elliptical mirror arrangement, which provided a high efficacy and an even illumination of the preparation. The light spot in the focus was larger in diameter than one would expect from a lamp with $7 \mathrm{~mm}$ arc length. This effect was due to the fact that the discharge was not only limited to the arc between the anode and cathode but more or less extended through the whole $15 \mathrm{~mm}$ diameter bulb of the xenon lamp. A frame by frame analysis of images recorded on videotape of the flash on a graduated grey screen in the focus revealed that an intense spot in the focus with a diameter of $5 \mathrm{~mm}$ was surrounded by a larger less intense spot with a total diameter of $30 \mathrm{~mm}$. This halo was reflected back to the preparation with the complementary elliptical reflector.

The efficacy of the light source was determined by measuring the free $\left[\mathrm{Ca}^{2+}\right]$ before and after flash 
in a $1.00 \mathrm{mM}$ Nitr5 solution using a Ca selective electrode. This method had the advantage of multidirectional sensitivity as opposed to most electronic detectors, which are sensitive in one direction only. A disadvantage of the arrangement could be a gradient in Ca release from the surface towards the middle of the container, which was earlier described by Lando and Zucker [9]. However this would imply that the measured calcium release is a conservative estimate as the diameter of a muscle preparation would be at least a factor 10 less.

Using a calcium selective electrode in combination with a peripheral junction reference electrode and a spacer ring (Fig. 2) enabled the analysis of a very small sample while preventing the efflux of the reference solution from directly influencing the contents of the sample.

It was found that the performance of the electrode depended on the order in which measurements were done if free $\left[\mathrm{Ca}^{2+}\right] \mathrm{s}$ were far apart. Therefore the low free $\left[\mathrm{Ca}^{2+}\right]$ range, the high free $\left[\mathrm{Ca}^{2+}\right]$ range and the steep part in the curve (Fig. 4) where saturation of Nitr5 occurred were measured in separate sessions to allow for intermediate $\mathrm{Ca}^{2+}$ reloading and stabilization of the electrode. In solutions containing $1.00 \mathrm{mM}$ Nitr5 and added $\left[\mathrm{Ca}^{2+}\right] \mathrm{s}$ below $10^{-}$ ${ }^{4} \mathrm{M}$ the free $\left[\mathrm{Ca}^{2+}\right]$ was reduced dramatically. The differences between the potentials measured in standard $\mathrm{Ca}$ solutions and those obtained in solutions with a low added $\left[\mathrm{Ca}^{2+}\right]$ can be explained by the strong $\mathrm{Ca}$ buffering capacity of Nitr5. This implies that in muscle experiments cells should be loaded slowly with Nitrs in order to prevent the intracellular $\left[\mathrm{Ca}^{2+}\right]$ from dropping too low. The buffering effect also explains why in lower added $\left[\mathrm{Ca}^{2+}\right] \mathrm{s}$ the response to a flash was decreased - all released $\mathrm{Ca}^{2+}$ is directly reabsorbed by empty 'cages'. The steep rise in free $\left[\mathrm{Ca}^{2+}\right]$ shown in the unphotolysed Nitr5 curve in Figure 4 between 0.87 and $1.07 \mathrm{mM}$ total $\left[\mathrm{Ca}^{2+}\right]$ can be explained by $\mathrm{Ca}^{2+}$ saturation of the empty cages of Nitr5 in this region. Therefore a flash evokes the largest increase in free $\left[\mathrm{Ca}^{2+}\right]$ in this region. As each Nitr5 molecule can contain $1 \mathrm{Ca}^{2+}$ molecule, the horizontal position of this saturation region in the free $\left[\mathrm{Ca}^{2+}\right]-$ total $\left[\mathrm{Ca}^{2+}\right]$ plot indicates the point where total $\left[\mathrm{Ca}^{2+}\right]$ equals [Nitr5]. This was used as described in the Results section to estimate that $1.00 \mathrm{mM}$ of Nitr5 initially contained $0.77 \mathrm{mM} \mathrm{Ca}^{2+}$.

Figure 4 shows that 5 flashes increased the free $\left[\mathrm{Ca}^{2+}\right]$ markedly in the range between $0.92-1.07$ $\mathrm{mM}$ total $\left[\mathrm{Ca}^{2+}\right]$. The amplitude of the calcium jump, which can be read from the $y$ axis, was variable along this range. By interpolation we can estimate that at a free $\left[\mathrm{Ca}^{2+}\right]$ of $10^{-7} \mathrm{M}$, which corresponds approximately to the intracellular $\left[\mathrm{Ca}^{2+}\right]$ of a muscle cell in the relaxed state, 5 UV flashes would evoke an increase in free $\left[\mathrm{Ca}^{2+}\right]$ to $1.7 \times 10^{-5} \mathrm{M}$. Such an increase in free $\left[\mathrm{Ca}^{2+}\right]$ in the $20 \mu \mathrm{l}$ sample is similar to or greater than the physiological calcium jump that has been measured intracellularly upon stimulation [14]. At $0.97 \mathrm{mM}$ total $\left[\mathrm{Ca}^{2+}\right]$ which corresponds to $10^{-6} \mathrm{M}$ free $\left[\mathrm{Ca}^{2+}\right]$ a maximum response to 5 flashes of $2.6 \times 10^{-5} \mathrm{M}$ free $\left[\mathrm{Ca}^{2+}\right]$ was found. The fact that the free $\left[\mathrm{Ca}^{2+}\right]$ increase in response to UV flashes was variable along the range of added $\left[\mathrm{Ca}^{2+}\right]$ values can partly be understood by describing the tested solution as a system of two competing buffers, i.e. unflashed Nitr5 and flashed Nitr5. It was attempted to estimate the amount of Nitr5 that was photolysed to give the effect shown in Figure 4 by using the equations for this system described in the Appendix. The 6 dotted lines show simulated data based on a total [Nitr5] of $1.00 \mathrm{mM}$ and depict different ratios of unphotolysed Nitr5 to photolysed Nitr5. The degree of photolysis increases from 0 to $50 \%$ in steps of $10 \%$. To realize a closer resemblance of the experimental and the calculated data, it was necessary to decrease the dissociation constants $\mathrm{Kd}$ of both flashed and unflashed Nitr5 used in other studies [1]. It can be seen in Figure 4 that experimental data from unflashed controls resembled closely a line calculated using a $\mathrm{Kd}$ of $1.81 \mathrm{nM}$, which is a factor 80 less than the dot-dashed line calculated using a Kd of $145 \mathrm{nM}$ [1]. Similarly, the dissociation constant for flashed Nitr5 was decreased to 75 $\mathrm{nM}$. The lower $\mathrm{Kd}$ values can be explained by the factor 10 lower ionic strength that was used in the present experiments as compared to the ionic strength $(100 \mathrm{mM})$ for which the $\mathrm{Kd}$ values were determined in other studies [1]. The present experiments were performed at this low ionic strength (10 $\mathrm{mM})$ in order to be able to measure lower $\left[\mathrm{Ca}^{2+}\right] \mathrm{s}$, according to the Orion $\mathrm{Ca}^{2+}$ selective electrode manual. For EGTA [15] it has been shown that the Kd 
value decreases with decreasing ionic strength. By using the formula described by Thomas [15], we calculated that the $\mathrm{Kd}$ for Nitr5 would decrease 2fold with a 10-fold decrease in ionic strength. It can thus be questioned whether the formula $(2.11$ in [15]) properly describes the relationship between $\mathrm{Kd}$ and ionic strength, considering the very low $\mathrm{Kd}$ value in the present experimental data. When comparing the calculated dotted lines in Figure 4 with the lines representing the experimental data, a more or less similar shape is seen. In the lowest range of the theoretical curve experimental data could not be collected because free $\left[\mathrm{Ca}^{2+}\right] \mathrm{s}$ lower than $10^{-8} \mathrm{M}$ could not be measured with the used electrode and total $\left[\mathrm{Ca}^{2+}\right] \mathrm{s}$ lower than $0.77 \mathrm{mM}$ could not be attained as this amount was bound to the $1.00 \mathrm{mM}$ Nitr5. When comparing photolysed to unphotolysed curves, it seems (other than in the theoretical curves) that the shape of both curves is similar but that the experimental photolysed curve is more shifted to the left. This effect can be observed most clearly around $1.00 \mathrm{mM}$ total $\left[\mathrm{Ca}^{2+}\right]$ in Figure 4 and is more likely due to a reduction of overall buffer capacity than to an altered Kd of the same buffer. This could be the case when the UV light destroys the cages rather than changes the buffering properties. In the light of these uncertainties it is not possible to calculate a precise ratio of photolysed to unphotolysed Nitr5 in this manner.

It can be concluded that the effect of photolysis on free $\left[\mathrm{Ca}^{2+}\right]$ is critically dependent upon the total $\left[\mathrm{Ca}^{2+}\right]$, as can be seen in both experimental and calculated data in Figure 4. The figure also shows that there is a very small range of total $\left[\mathrm{Ca}^{2+}\right]$ values in which free $\left[\mathrm{Ca}^{2+}\right]$ values similar to intracellular $\left[\mathrm{Ca}^{2+}\right]$ values can be attained. This indicates that the strong buffering capacity of Nitr5 intracellularly, i.e. when loaded as the Nitr5-acetoxymethyl ester, makes high demands on the calcium homeostasis mechanism of the cell, and might even interfere to a large extent with this mechanism.

In order to obtain a more distinct effect of the UV exposure initially 5 flashes were applied instead of 1 flash. In later experiments, it was shown that the effect of 5 flashes measured in $1.00 \mathrm{mM}$ Nitr5 with a $2.3 \times 10^{-4} \mathrm{M}$ added $\left[\mathrm{Ca}^{2+}\right]$ was not 5-times but only 1.5-times higher than the effect of 1 flash (see Fig.5). So as opposed to a $1.7 \times 10^{-5} \mathrm{M} \mathrm{Ca}^{2+}$ jump in response to 5 flashes a $1.1 \times 10^{-5} \mathrm{M} \mathrm{Ca}^{2+}$ jump would be attainable in response to 1 flash. Also the effect of the complementary second elliptical mirror was investigated. With this second mirror the response was 2-fold enhanced, which can be exactly explained by the illumination of the preparation from both sides. A $3 \mathrm{~mm}$ thick Schott UG11 filter decreased the increase in free $\left[\mathrm{Ca}^{2+}\right]$ by $3 \%$, which indicates that the effect measured is mainly evoked by UV light with a wavelength between $320-370 \mathrm{~nm}$.

This study indicates that it is possible using one flash from a low-cost UV flash unit $(\$ 1500)$ to evoke a physiological $\left[\mathrm{Ca}^{2+}\right]$ jump, from $10^{-7}$ to 1.1 $\times 10^{-5} \mathrm{M}$, in a $20 \mu \mathrm{l}$ sample containing $1.00 \mathrm{mM}$ Nitr5. It is most likely that the effect in a smaller sized (smooth) muscle preparation will be more distinct Measurement of the free $\left[\mathrm{Ca}^{2+}\right]$ increase using an ion selective electrode appears to be a useful tool to analyze both the behaviour of Nitr5 and the efficacy of the flash for photolysis.

\section{Acknowledgements}

We are grateful to J.B.F. Ekas and H.J. Wong-Loi-Sing, Central Instrumentation Department, Erasmus University Rotterdam and P. Strzelczyk, dipl.Ing. and R. Zartner, EG\&G-Heimann Optoelectronics Gmbh, Wiesbaden, Germany for their technical advice and assistance, to Dr H.R. de Jonge and Dr B.C. Tilly, Department of Biochemistry, Erasmus University Rotterdam for biochemical advice and to C. Canion, Euro Biochem s.c.r.l., Bierges, Belgium for his support.

This work was funded by grant cgo.1061 from the Dutch Kidney Foundation.

\section{References}

1. Gumcy AM. Taien RY. Lester HA. (1987) Activation of a potassium current by rapid photochemically generated step increases of intrucelluler calcium in rat sympathetic neurons. Proc. Natl Acad. Sci. USA., 84, 3496-3500.

2. Malenka RC. Kever JA. Zucker RS. Nicoll RA. (1988) Potuynotic enlaimen is afficient for potentiotion of hippocampal syappic tranomision. Science, 242, 81-84.

3. Le TJ. Ashley $\mathrm{CC}$ (1990) $\mathrm{Ca}^{2+}$ release from the sarcoplasmatic reticulum of barmacle myofibrillar bundles initiated by photolysis of caged $\mathrm{Ca}^{2+}$. J. Physiol. (Lond.), 427, $435-453$.

4. Lea TJ. Fenton MJ. Potter JD. Ashley CC. (1990) Rapid 
activation by photolysis of nitr-S in akinned fibses of striated adductor muscle from the scallop. Biochim. Biophys. Acta, 1034, 186-194.

5. Van Koeveringe GA. van Mastrigt R. (1991) Excitatory pathways in smooth muscle investignted by phase-plot analysis of isometric force development. Am. J. Physiol., 261, R138-R144.

6. Nabauer M. Morad M. (1990) $\mathrm{Ca}^{2+}$ induced $\mathrm{Ca}^{2+}$ welease as examined by photolysis of caged $\mathrm{Ca}^{2+}$ in single ventricular myocytes. Am. J. Physiol., 258, C189-Cl93.

7. Niggli E. Lederer WJ. (1990) Voltage-independent calcium release in heart muscle. Science, 250, 565-568.

8. Valdeolmillos M. O'Neill SC. Smith GL. Eisner DA. (1989) Calcium-induced calcium release activates contraction in intact cardiac cells. Pflugers Arch., 413, 676-678.

9. Lando L. Zucker RS. (1989) 'Caged calcium' in aplasia pacemaker neurons. Characterization of calcium-activated potassium and nonspecific cation currents. J. Gen. Physiol, $93,1017-1060$.

10. Tsien RY. Zucker RS. (19) Control of cytoplaumic calcium with photolabile tetracarboxilate 2-nitrobenzhydrol chelators. Biophys. J., 50, 843-853.

11. Rapp G. Gath K. (1988) A low cost high intensity flash device for photolysis experiments. Pflugers Arch., 411, 200-203.

12. Edgerton HE. (1979) Electronic flash, strobe. Cambridge, MA, MIT Press, pp 6-47.

13. Phillips R. (1983) Sources and applications of ultraviolet radiation. London, Academic Press, pp 303-331.

14. Yagi S. Becker PL. Fay FS.(1988) Relationship between force and $\mathrm{Ca}^{2+}$ concentration in smooth muscle as revealed by measurements on single cells. Proc. Natl Acad. Sci. USA, 85, $4109-4113$.

15. Thomas MV. (1982) Techniques in calcium research London, Academic Press., pp 40-45.

16. Zucker RS. Steinhardt RA. (1978) Prevention of the cortical reaction in fertilized sea urchin eggs by injection of calcium-chelating ligands. Biochim. Biophys. Acta, 541, 459-466.

Please send reprint requests to: Dr G.A. van Koeveringe, Department of Urology, Division of Urodynamics, Room Ee 1630, Erasmus University Rotterdam, PO Box 1738, 3000 DR Rotterdam, The Netherlands.

Received : 25 August 1993

Accepted : 27 January 1994

\section{APPENDIX}

The relation of total $\left[\mathrm{Ca}^{2+}\right]$ to free $\left[\mathrm{Ca}^{2+}\right]$ in a solution containing 2 competing buffers, in this case photolysed and unphotolysed Nitr5, can be described according to Zucker and Steinhardt [16].

In such a solution the total calcium concentration ([CaT]) consists of free calcium ([CaF]) and calcium bound to both buffers:
$[\mathrm{Car}]=[\mathrm{CaF}]+$

$$
\begin{aligned}
& {\left[\mathrm{Ca}^{2+}\right] \text { bound to unphotolysed Nitr5 }+} \\
& {\left[\mathrm{Ca}^{2+}\right] \text { bound to photolysed Nitr5 }}
\end{aligned}
$$

Eq. 1

by introducing a dissociation constant $\mathrm{KU}$ for calcium binding to unphotolysed Nitr5 with a concentration of [NsU]:

$\left[\mathrm{Ca}^{2+}\right]$ bound to unphotolysed Nitr5 $=\frac{[\mathrm{CaF}] \cdot\left[\mathrm{N}_{5} \mathrm{U}\right]}{\mathrm{Kd}+[\mathrm{CaF}]}$

Eq. 2

and a similar dissociation constant $K_{P}$ for calcium binding to photolysed Nitr5 with concentration [NsP], Equation 1 can be rewritten as follows:

$[\mathrm{CaT}]=[\mathrm{CaF}]\left(1+\frac{\left[\mathrm{NsU}_{5}\right]}{\mathrm{KU}_{\mathrm{U}}+[\mathrm{CaF}]}+\frac{\left[\mathrm{N}_{5} \mathrm{P}\right]}{\mathrm{KP}_{\mathrm{P}}+[\mathrm{CaF}]}\right)$

Eq. 3

Reduction to one denominator gives:

$$
\begin{array}{r}
{[\mathrm{CaF}]^{3}+\left(\mathrm{KU}_{\mathrm{U}}+\mathrm{KP}-[\mathrm{CaT}]+[\mathrm{N} s \mathrm{U}]+\left[\mathrm{N}_{5} \mathrm{P}\right]\right)[\mathrm{CaF}]^{2}} \\
+\left\{\mathrm{K}_{\mathrm{P}}\left[\mathrm{N}_{5} \mathrm{U}\right]+\mathrm{KU}[\mathrm{NsP}]-[\mathrm{CaT}]\left(\mathrm{KU}+\mathrm{KP}_{5}\right)\right. \\
\left.+\mathrm{KUK}_{\mathrm{P}}\right\}[\mathrm{CaF}]-\mathrm{KUK}_{\mathrm{P}}[\mathrm{CaT}]=0
\end{array}
$$

Eq. 4

Using the computer program MATLABE total $\left[\mathrm{Ca}^{2+}\right] \mathrm{s}$ were calculated for 100 equally spaced free $\left[\mathrm{Ca}^{2+}\right]$ values between $10^{-8}$ and $10^{-3} \mathrm{M}$ and 6 different ratios of $\left[\mathrm{N}_{5} \mathrm{U}\right]$ and $[\mathrm{Ns} \mathrm{P}]$. $\mathrm{Kd}$ values (for $10 \mathrm{mM}$ ionic strength) of $1.81 \mathrm{nM}$ and $75 \mathrm{nM}$ were used. For comparison an extra curve was calculated using the dissociation constant for unphotolysed Nitr5 at $100 \mathrm{mM}$ ionic strength [1]. The curves were plotted on logarithmic axes, as shown in Figure 4. The steeply increasing part of the experimental data curve was shifted to coincide with the calculated data curve by addition of $7.7 \times 10^{-4}$ to the added $\left[\mathrm{Ca}^{2+}\right]$ values which represents the $\left[\mathrm{Ca}^{2+}\right]$ bound to $1.00 \mathrm{mM}$ Nitr5. 